International Journal of Engineering \& Technology, 7 (3.27) (2018) 348-351
International Journal of Engineering \& Technology
SPC
Website: www.sciencepubco.com/index.php/IJET
Research paper

\title{
Transition in Adolescents: a Study on Changes in Social Cohesion
}

\author{
M.C. Jaison ${ }^{1 *}$, N. Prathiba ${ }^{2}$ L. Ranjit ${ }^{3}$ \\ ${ }^{1}$ Research Scholar, Department of Social Work, Karpagam University. \\ ${ }^{2}$ Associate-Professor, Department of Social-Work, Karpagam University, Coimbatore. \\ ${ }^{3}$ Assistant Professor and Head, Department of Social Work, NGM College, Pollachi.
}

\begin{abstract}
Human growth begins with conception and developed through different unique stages and ends with death. Each stage has its own characteristics. Adolescent period is also one of such unique period in Human Growth. Even though there are development in physical health of adolescent during these decades mental health of adolescent is not marked such evidential growth in overall mental health. Since Adolescent period is the important and crucial period of moulding mental health. Department of Health, Republic of South Africa in 2001 mentioned four dimensions of adolescent mental health. They are mental, emotional, social and spiritual. The study primarily focuses on the social dimension of adolescent mental health.
\end{abstract}

Keywords: Adolescence, physical health, mental health, social dimension.

\section{Introduction}

According to the World Health Organization (WHO Adolescent is a period of transition from childhood to adulthood with rapid intellectual growth. In this period Adolescents thinks that they knows everything about anything and everything than their parents and their teacher. Human development has various stages with its own unique characteristics. The stages are basically begins with Infancy and passes through Childhood and Adolescence. Adulthood and Old age are the later stages of development. In these development stages Adolescent period is the crucial and most important period of a person with lots of identity crisis and confusions with lots of misunderstandings. It's because of the various physical and psychological and reproductive changes happening in their body and mind. Therefore it's not the age but the proper understanding about once own change and achieving required developmental mile stones. According to Mc Craken Social cohesion is characterised by a society dealing with connection and relations between the social unit, individuals, groups, association as well as territorial units (Mc Craken, 1998). Emile Durkheim was the first person who coined the concept of Social Cohesion, as feature which gives order in the society and makes the interdependence between the members of society with shared loyalties and solidarity. Five dimensions of Social cohesion are Belonging- Isolation, Inclusion -exclusion, Participation - Non-involvement, Recognition Rejection and Legitimacy - Illegitimacy

According to Buchanan and Hughes Adolescent age is the period of different types of stress, various storm and changes of intense moodiness (Buchanan \& Hughes, 2009). Family is the most important supporting system available to the child. Relationship with parents is an important factor in moulding the adolescent personality. In adolescent period adolescent have poor reputation to their parents and which makes lots of confusion between them. It can be difference of opinion, difficulty in obeying parents, communication barriers and emotional out bursting. In this adolescent period adolescent learns lots of things from their peers but parents have vital role to mould them and helping to achieve each developmental mile stones. .Laurence Steinberg and his colleagues (1992) in their study found that adolescents who's both friends and parents support in academic achievement perform better than adolescents who receive support from only one, or neither. So it's needed both parents and peers for a healthy development of an adolescent in their adolescent period. According to Steinberg and Silverberg "Adolescents are less influenced by friends when they have close and involving relationships with their parents" (Steinberg and Silverberg 1986). Biological, cognitive, and emotional transitions are the major changes in adolescence in the social transition of adolescence. There for the parents need to give more care and attention in those areas. There for many studies conducted in those areas especially the relationship between adolescent and parents, adolescent and peers, and influence between these. The influence of peers has great deal in social transition of and adolescent. There for spending time with peers has great influence and the amount of time with peers decides the impact.

In adolescent period many children will think that family is less important and they will be in intimacy with opposite sex in dating relation or deep emotional relationship. It may start in early adolescence or middle or late adolescence. It differs according to each individual. Dating relationships begin in 13 years of age for girls and 14 years of age for boys with genuine intimacy. Even though there is a relationship problem between parents and teenagers, when they become mature the relationship gets again bonded between parents and adolescents.

Adolescent time is a period of emotional ups and downs young people are confused with what to do, what not to do, when to do and with whom to do and so on. Very often the peer relation can cause stress between parental relationships. So support from parent and understanding parent can make easy to go through such stress. Family have to support their child in this period so that the 
child may get self-confidence and self-efficacy to build brighter future.

In the year 2015 Times of India reported that the survey conducted by WHO \& Studies on Health Behaviour in School aged Children says 10- $20 \%$ of the children are having social cohesion and have one or more mental or behavioural problems. The nation gives much importance to adolescent related issues which is evident through the different programs and conventions organized all around the nation. Goa State Adolescent Convention was based on the topic "Reproductive and social health of adolescents" (Times of India) The same newspaper on June 28 , 2015 reported an interesting news that Rajasthan to observe Adolescent Health Day 4 times a year. The Health experts who attended the session declared that adolescents undergo physical, emotional and behavioural changes which need care and guidance in order to prevent worsening of adolescent issues

\section{Objective of the Study}

To study the influence of transition in adolescent on social cohesion

To study the socio-demographic details of respondents.

To analyse the influence of social transition on cohesion in family. To understand the influence of cognitive transition on social cohesion in school environment

To identify whether social participation is affected by emotional and physical transition

\section{Research Design}

The research design used was Descriptive research design, with an intention to add more information to the existing ones, so that it could contribute to the mental health improvement of adolescents. A lot of studies have been conducted on topics that are related to adolescents and their problems. Poor social cohesion is one of those major problems faced by adolescents. So the researcher conducted the study among the middle adolescents regarding their transition during adolescence and its influence on their social cohesion in order to gain detailed information that can be added to the existing ones.

The target group of the study is the middle adolescents in Infant Jesus Public School. The researcher decided to choose 20 students each from $10^{\text {th }}, 11^{\text {th }}$ and $12^{\text {th }}$ grade using Random Number method of Simple random sampling. Using random number method every 5th student in the register list of each grade was selected from total number of students in each grade. The study was conducted in Paravur Municipality in the Ernakulum District, specifically in Infant Jesus Public School. Paravur is historically important and years old municipality and has recorded fast growth in its development. Even though it's part of Kochi it's situated $17 \mathrm{~km}$ away from Kochi. The sample for the study (data) collected from sixty middle adolescents of Infant Jesus Public School using is Questionnaire (primary method of the data collection). The data analysed and interpreted using IBM-SPSS. This was an accurate way since correct analysis of responses of the respondents could be properly analysed.

\section{Result and Discussions}

The study shows that vast majority of the respondents (90\%) are belong to the age group of 16 and rest in the category of age of 17 .

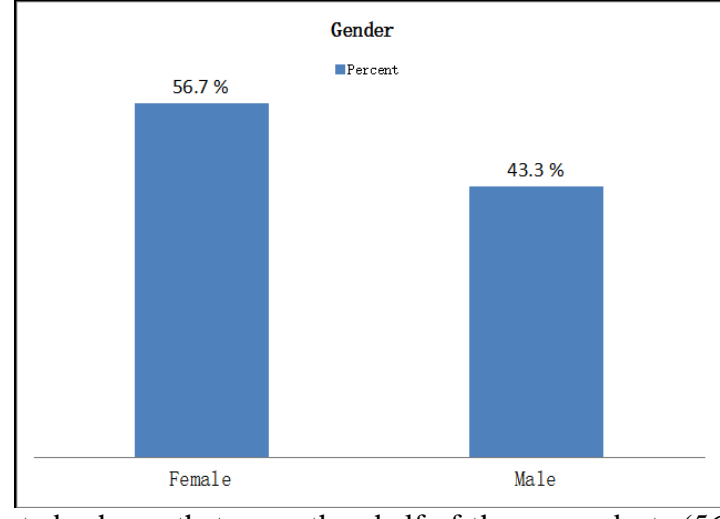

The study shows that more than half of the respondents $(56.7 \%)$ are female.

Spend more time with friends than family

- Agree $\quad$ Partially Agree $\quad$ Partially Disagree -Disagree

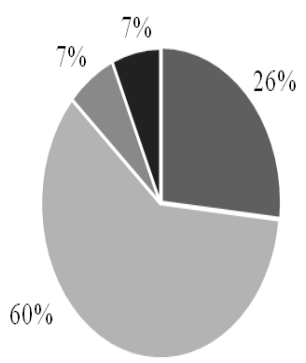

The above diagram shows that Majority of adolescents (60\%) spend their time with friends than their own family members. Adolescence are willing to share their daily experiences with their family members, but they prefer friends in the case of their personal issues. Majority of adolescents are ready to sacrifice a trip with their family in order to enjoy with their friends which shows that their adolescence friends become more important.

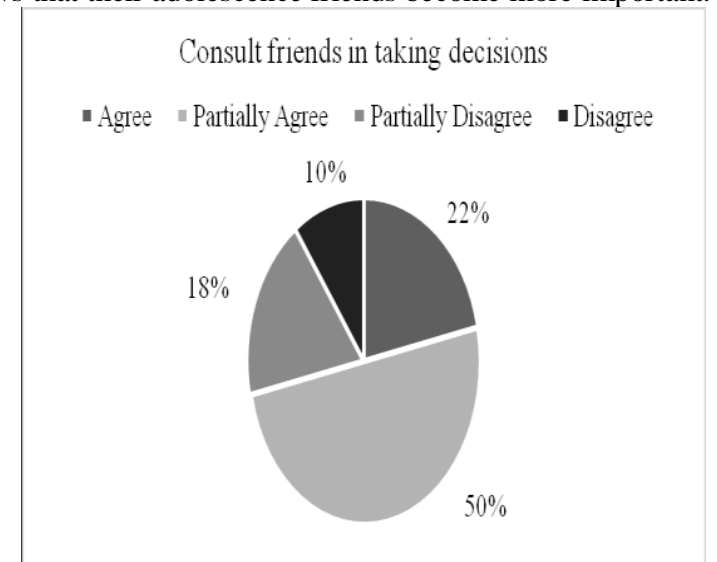

The diagram shows that $50 \%$ of the adolescents partially agree and $22 \%$ of the adolescents completely agree, $18 \%$ partially disagree and $10 \%$ disagree that they consult friends in taking decisions.

$55 \%$ of respondents feel that they are most accepted among their friends than among their family members.

Majority of adolescence (41.67\%) are of the opinion that their friends are more supportive than their family which shows the reduced cohesion with their family during adolescence. 


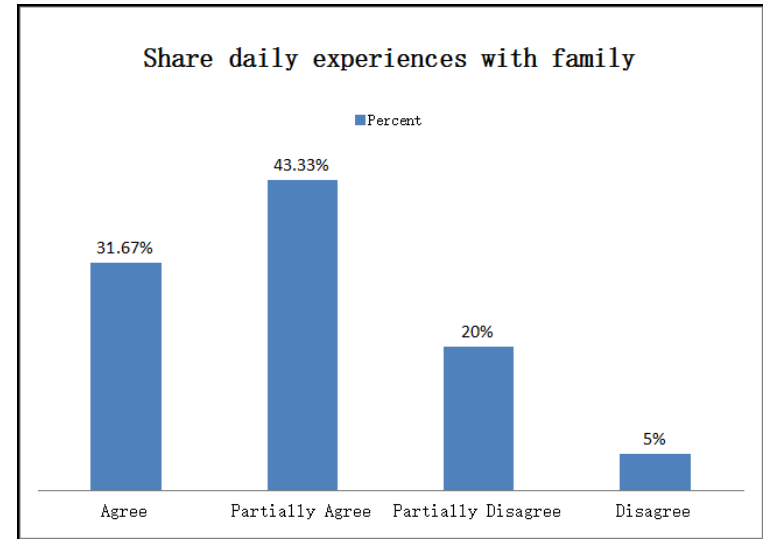

The graph shows that $31.67 \%$ of adolescent completely agree that they share their daily experiences with family and only $5 \%$ of them disagree to the statement. $43 \%$ partially agree and $20 \%$ partially disagree. Adolescents tend to express their feelings and emotions before their friends more than to their family which shows that their interaction and cohesion to their family members are reduced during this period of their life. During adolescence majority of the adolescents depend on their friends for solving problems.

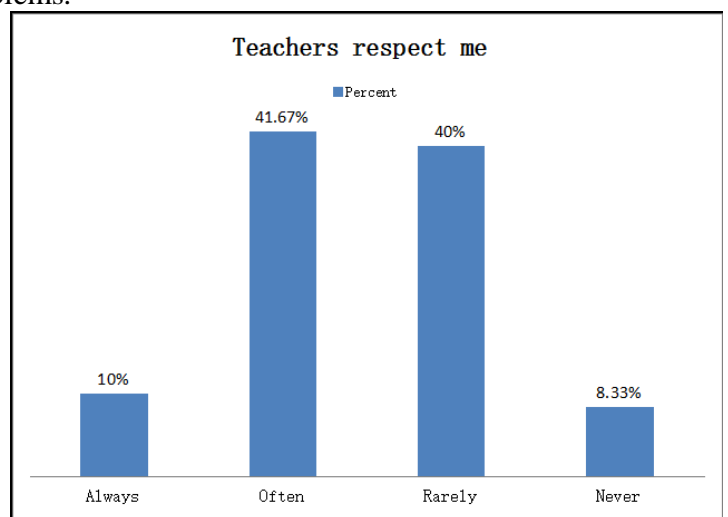

Majority of the adolescent (40\%) respondents are of the opinion that they are rarely respected by their teachers. The adolescents hesitate to share their problems to the teachers due to the poor social cohesion with their teachers. During adolescence, children often get in to conflict with their teachers and they occurs a difference in opinion due to their changing thoughts.

The study shows adolescents $(68 \%)$ tend to be more expert in getting along well with their peers than with their teachers which shows their reduced social cohesion with their teachers.

$60 \%$ of the adolescents are of the opinion that they rarely get along well with teachers.50\% of respondents rarely talk to their teachers outside class room. In order to have a good social cohesion with teachers, proper interaction between them is also necessary. But the data shows that majority of the adolescent do not do a proper interaction with their teachers outside classroom.

More reasoning and critical nature during adolescence make them angry $(65 \%)$ and make them react when they are criticized. They do it to teachers and friends in the school atmosphere which actually reduces their social cohesion with them. [27]

Majority of adolescents in the study (52\%) often avoid social interaction due to their shyness regarding their physical changes.

Adolescents who refuse to actively take part in social gathering used to be more confident in social participation during their childhood (48\%), which indicates that the transition that they have undergone during adolescence have affected their social participation and social cohesion. [28]

In the study others' reviews and opinions affect the selfunderstanding of about $56.67 \%$ of respondents.

\section{Conclusion}

Adolescents are the most important asset of the nation. The research is conducted on the basis of the WHO report on health behaviour of adolescents which says that $10-20 \%$ of adolescents are poor in social cohesion and have one or more mental health problems.

The study shows that the transition in adolescents may affect their social cohesion in family, school as well as society.

The study can be used for improving the social cohesion and mental health of an adolescent. Many researchers have been conducted in topics related to adolescents and social cohesion is equally important as human is a social being.

Social workers have got great roles to play in improving the life of adolescents.

The second decade of a human life is considered as a period of stress and storm which can be made more beautiful by the social work interventions.

The problems that an adolescent faces can have adverse effect on their social cohesion and mental health. These problems must be identified and timely intervention should be made through detailed researches and social work methods in order to build a powerful adolescent group.

This can be done by the joint efforts of social workers, family members, school authorities, and government authorities as well.

\section{References}

[1] Anderson M, Goodman J \& Schlossberg KN, Adults in Transition, New York: Springer publishing company, (2011).

[2] Damon W, Handbook of Child Psychology, Social, Emotional, and Personality Development, Canada, NY: J. Wiley, (2006).

[3] Hartup WW, "Peer Experience and Its Developmental Significance", Developmental Psychology: Achievements and Prospects, ed. M. Bennett. Philadelphia: Psychology Press, (1999).

[4] Hebert TP, "Social and emotional characteristics and Traits of Gifted Young People", Understanding the social and emotional lives of gifted students. Waco, Tex.: Prufrock Press. (2011)

[5] Mounts NS \& Steinberg L, "An Ecological Analysis of Peer Influence on Adolescent Grade Point Average and Drug Use", Developmental Psychology, Vol.31, No.6, (1995), pp.915-922.

[6] Rathus AS, Childhood and Adolescence: Voyages in Development, USA, Wadsworth, (2013).

[7] Rogers C, On becoming a person, Boston: Houghton Mifflin, (1969).

[8] Savin-Williams RC \& Berndt TJ, Friendships and Peer Relations during Adolescence, At the Threshold: The Developing Adolescent, ed. S. S. Feldman and G. R. Elliott. Cambridge, MA: Harvard University Press, 1990.

[9] Shuayb M, Rethinking Education for Social Cohesion, UK, Macmillan Publishers, (2012).

[10] Steinberg L \& Levine A, You and Your Adolescent: A Parent's Guide for Ages 10 to 20, New York: Harper Perennial, (1991).

Steinberg L, Adolescence. 4th ed. New York: McGraw-Hill, (1996).

Bandhana SPD, "Home environment, mental health and academic achievement among higher secondary school students", International Journal of Scientific and Research Publications, Vol.2, No.5, (2012).

[13] Herman KC, Osteander R, Tucker CM, "Do family environments and negative cognition of adolescents with depressive sympots vary by ethenic group", Journal of Family Psychology, Vol.21, (2007), pp.325-330.

[14] McKeown RE, Garrison CZ, Jackson KL, Cuffe SP, Addy CL \& Waller JL, "Family structure and cohesion, and depressive symptoms in adolescents", Journal of Research on Adolescence, Vol.7, (1997), pp.267-282.

[15] Mohanraj RL, "Perceived family environment in relation to adjustment and academic achievement", Journal of the Indian Academy of applied Psychology, Vol.31, (2005), pp.18-23.

[16] Ozcinar Z, "The instructional communicative qualification of parents with students", Cypriot Journal of Education Science, Vol.1, (2006), pp.24-30. 
[17] Patrick H, Ryan AM, Alfeld-Liro C, Fredricks JA, Hruda LZ \& Eccles JS, "Adolescents' Commitment to Developing Talent: The Role of Peers in Continuing Motivation for Sports and the Arts", Journal of Youth and Adolescence, Vol.28, No.6, (1999), [38] pp.741-763.

[18] Reinherz MZ, Stewart-Berghauer G, Pakiz B, Frost AK \& Moeykens BA, "The relationship of early risk and current mediators to depressive symptomology in adolescence", Journal of the American Academy of Child and Adolescent Psychiatry, Vol.28, (1989), pp.134-142.

[19] Shek DTL, "Family environment and adolescent Psychological welling, school adjustment, and problem behavior: A pioneer study is a Chinese context", Journal of Genetic Psychology, Vol.158, No.1, (1997), pp.113-128.

[20] Wentzel KR \& Feldman SS, "Relations of cohesion and power in family dyads to social and emotional adjustment during early adolescence", Journal of Research on Adolescences, Vol.2, (1996), pp.225-245.

[21] Bhatia H \& Chadha NK, "Family Environment Scale", Lucknow: Ankur Psychological Agency, 1993.

[22] Collins WA, Hennighausen KC, Schmit DT \& Sroufe LA, "Developmental precursors of romantic relationships: A longitudinal analysis", New Directions for Child and Adolescent Development, Vol.78, (1997), pp.69-84.

[23] Frasch KM \& Brooks D, "Normative development in transracial adoptive families: Integration of the literature and implications for the construction of theoretical framework", Families in society, Vol.84, No.2, (2003), pp.201-13.

[24] Gauze C, Bukowski WM, Aquan-Assee J \& Sippola LK, "Interactions between family environment and friendship and associations with self-perceived well-being during early adolescence", Child development, Vol.67, No.5, (1996), pp.2201-2216.

[25] Omotoso, Adolescents transition: The challenges and the way out, Department of health promotion and education, College of Medicine, Ibadan, Nigeria, (2007).

[26] Steinberg L, "Cognitive and affective development in adolescence", Trends in Cognitive Sciences, (2005), pp.51-58.

[27] G, Abikhanova, A Ahmetbekova, E Bayat, A Donbaeva, G Burkitbay (2018). International motifs and plots in the Kazakh epics in China (on the materials of the Kazakh epics in China), Opción, Año 33, No. 85. 20-43.

[28] G Ainabekova, Z Bayanbayeva, B Joldasbekova, A Zhaksylykov (2018). The author in esthetic activity and the functional text (on the basis of V. Mikhaylov's narrative ("The chronicle of the great jute"). Opción, Año 33. 63-80.

[29] Psychology Encyclopedia, Adolescence - Puberty, Cognitive transition, Emotional transition, Social transition, (2010). Retrieved from http://psychology.jrank.org/pages/14/Adolescence.html

[30] World Health Organization, Adolescent health research priorities: report of a technical consultation, (2015). Retrieved from http://www.who.int/maternal_child_adolescent/documents/ adolescent -research -priorities-consultation/en/

[31] Martin Lynn C \& Fabes R, Discovering Child Development, (2008). Retrieved from: https://books.google.co.in

[32] Cox JM \& Brooks GJ, Conflict and Cohesion in Families: Causes and Consequences, (2013). Retrieved from: http: //www. kindleebooks.com

[33] Rajasthan to observe Adolescent Health Day 4 times a year, (2015). TNN. Retrieved from: http://timesofindia.indiatimes.com/

[34] Unicef selects Visakhapatnam district for pilot project on adolescents, (2015). TNN, Retrieved from http: //www. Times of india.indiatimes.com / The Times of India /

[35] Centre for Survey Research and Methodology, Social cohesion as an aspect of the Quality of Socities, (2000). Retrieved from http://www.gesis.org/fileadmin/upload/dienstleistung/daten /soz_ indikatoren /eusi/paper14.pdf

[36] US National Library of Medicine, School social cohesion, studentschool connectedness, and bullying in adolescents, (2015). Retrieved from :http://www.ncbi.nlm.nih.gov/pubmed/25878143
[37] Sharon L, Behavior Problems in Adolescents, (2014). Retrieved from: https://www.msdmanuals. com/professional /paediatrics /problems-in-adolescents/behavior-problems-in-adolescents Kamis, Cognitive Transitions in Youth, (2009). Retrieved from: http://www. stanfordchildrens.org/en/ topic/default? id=cognitivedevelopment-90-P01594.

[39] American Psychological Association Developing Adolescents, Washington, DC, (2002). Retrieved from: https://www.apa. org/ pi/families/resources/develop.pdf

[40] A publication of the ACT for Youth Center of Excellence, ParentChild Relations in Adolescence, (2002). Retrieved from: http:// www.actforyouth. net/resources/rf/rf_parent_0302.cfm

[41] Adolescene, Encyclopaedia of Child's Health, (2014). Retrieved from: http://www.healthofchildren.com/A/Adolescence 